\title{
Produção e comercialização de espécies vegetais nativas ornamentais no Rio Grande do Sul: normas legais e desafios
}

REVISTA ELETRÔNICA

CIENTÍFICA DA UERGS

Rosângela Gonçalves Rolim

Universidade Federal do Rio Grande do Sul (UFRGS).

E-mail: rosangelagrolim@yahoo.com.br, http://lattes.cnpq.br/5983569983483747

Gerhard Ernst Overbeck

Universidade Federal do Rio Grande do Sul (UFRGS).

E-mail: gerhard.overbeck@ufrgs.br, http://lattes.cnpq.br/7199331941689392

Elaine Biondo

Universidade Estadual do Rio Grande do Sul (UERGS).

E-mail: elaine-biondo@uergs.edu.br, http://lattes.cnpq.br/2 I58687538722378

ISSN 2448-0479. Submetido em: 01 dez. 2019. Aceito: 02 nov. 2020. DOI: http://dx.doi.org/10.21674/2448-0479.7I.30-40

\section{Resumo}

As espécies nativas vegetais no Estado do Rio Grande do Sul (RS) estão cada vez mais isoladas em fragmentos devido especialmente à conversão dos ecossistemas naturais, pelo uso de agrotóxicos e, ainda, ameaçadas pela possibilidade de erosão genética. A conservação pelo uso pode ser uma alternativa para garantir a perpetuação destas espécies, incluindo a possibilidade de utilização do potencial ornamental nativo. Com base em revisão da legislação estadual e federal vigentes no segundo semestre de 2018 , este trabalho elencou as principais etapas para legalização da produção e comercialização de mudas e sementes de espécies nativas para fins ornamentais no contexto do Estado do RS. Foram consultadas I.I 58 normas legais, dentre as quais 64 apresentavam informações acerca do tema. Com base nessa revisão observou-se a necessidade de determinadas etapas para obtenção de autorização para emprego comercial de plantas nativas na esfera ambiental e da agricultura, tanto estadual quanto federal. Atualmente há necessidade de realização de inúmeros procedimentos para produção e comercialização de mudas e sementes nativas, e em mais de um órgão, quando comparado aos procedimentos para conversão de vegetação, para a qual pode ser necessário recorrer a um único órgão. Este exemplo expõe as dificuldades para utilização sustentável da biodiversidade nativa em detrimento de atividades degradadoras, e desestimula ou inviabiliza a iniciativa de pessoas no ramo. O RS avançou no processo para uso sustentável de plantas nativas nas últimas décadas, mas há necessidade de construção de políticas ambientais que estimulem estas atividades e ainda garantam a conservação genética.

Palavras-chave: Plantas nativas ornamentais. Uso sustentável. Legislação brasileira. Conservação.

\section{Abstract}

\section{Production and commercialization of native ornamental plant species in Rio Grande do Sul: legal norms and challenges}

Native species in Rio Grande do Sul (RS) State are increasingly isolated in fragments due especially to the conversion of natural ecosystems, the use of pesticides and, still, threatened by the possibility of genetic erosion. Conservation by use can be an alternative to guarantee the perpetuation of these species, including the possibility of using the native ornamental potential. Based on a review of the state and federal legislation in force in the second half of 2018 , this work listed the main steps for legalizing the production and commercialization of seedlings and seeds of native species for ornamental purposes in the context of RS State. 
Of the II 58 consulted legal norms, 64 presented information on the topic. Based on this review, there is the need for certain steps to obtain authorization for commercial use of native plants in the environmental and agricultural spheres, both state and federal. Currently, there is a need to carry out numerous procedures for the production and commercialization of native seedlings and seeds, and in more than one agency, when compared to the procedures for conversion of vegetation, for which it may be necessary to resort to a single agency. This example exposes the difficulties for sustainable use of native biodiversity to the detriment of degrading activities, and discourages or prevents the initiative of people in the activity. RS has advanced in the process for the sustainable use of native plants in the last decades, but there is a need to build environmental policies that encourage these activities and still guarantee genetic conservation.

Keywords: Ornamental native plants. Sustainable use. Brazilian legislation. Conservation.

\section{Resumen}

\section{Producción y comercialización de especies de plantas nativas ornamentales en Rio Grande do Sul: normas legales y desafíos}

Las especies de plantas nativas en el Estado de Rio Grande do Sul (RS) están cada vez más aisladas en fragmentos debido especialmente a la conversión de ecosistemas naturales, por el uso de pesticidas y, aún, amenazadas por la posibilidad de erosión genética. La conservación por uso puede ser una alternativa para garantizar la perpetuación de estas especies, incluida la posibilidad de aprovechar del potencial ornamental nativo. Con base en una revisión de la legislación estatal y federal vigente en el segundo semestre de 2018, este trabajo enumeró los principales pasos para legalizar la producción y comercialización de plántulas y semillas de especies nativas con fines ornamentales en el contexto del Estado de RS. Se consultaron I, I58 normas legales, de las cuales 64 presentaron información sobre el tema. Con base en esta revisión, se observó la necesidad de ciertos pasos para obtener la autorización para el uso comercial de plantas nativas en las esferas ambiental y agrícola, tanto estatal como federal. Actualmente, existe la necesidad de realizar numerosos procedimientos para la producción y comercialización de plántulas y semillas nativas, y en más de un órgano, en comparación con los procedimientos de conversión de vegetación, para lo cual puede ser necesario recurrir a un solo órgano. Este ejemplo expone las dificultades para el uso sostenible de la biodiversidad nativa en detrimento de actividades degradantes y desalienta o impide la iniciativa de las personas en la industria. El RS ha avanzado en el proceso de uso sustenible de plantas nativas en las últimas décadas, pero existe la necesidad de construir políticas ambientales que incentiven estas actividades y aún garanticen la conservación genética.

Palabras clave: Plantas nativas ornamentales. Uso sustenible. Legislación brasileña. Conservación.

\section{Introdução}

A vegetação florestal no Rio Grande do Sul (RS) teve aumento da sua cobertura nas últimas três décadas (758.797, I0 hectares) (MAPBIOMAS, [2020]), ao mesmo tempo em que ocorreu rápida conversão de áreas naturais campestres com 2.849.509,47 milhões de hectares convertidos (MAPBIOMAS, [2020]). Esta perda de vegetação natural ocorreu em função das mudanças no uso do solo durante este período, sendo a diminuição da pecuária sob campo nativo uma das principais mudanças. A atividade é considerada de uso sustentável dos campos nativos quando o mesmo não é submetido a pastejo intenso (OVERBECK et al., 2009; CARVALHO et al., 2009). No caso do sobrepastejo, sem histórico de outros usos, o retorno a um manejo adequado é geralmente suficiente para a recuperação da biodiversidade campestre (VIEIRA; OVERBECK, 20I5). No entanto, a vegetação nativa vem sendo substituída por plantio de culturas anuais (IBGE, I996; IBGE, 20I7; MAPBIOMAS, [2020]), principalmente por lavouras (de soja, milho e arroz), ou por silvicultura (eucaliptos, pinus e acácia) (VÉLEZ-MARTIN et al., 20I5), agravado pelo aumento no uso de agrotóxicos (IBAMA, 20I8). Estas ações de conversão, em parte sem autorização dos órgãos ambientais e, portanto, ilegais (IBAMA, 2017; WENZEL, [2018]), têm incidido num intenso isolamento de populações vegetais silvestres em fragmentos. Muitos relictos ainda existentes, como às margens de estradas, bordas de cursos d'água, baixadas alagáveis, 
têm suas populações naturais ameaçadas pela possibilidade de erosão genética (SILVA; PERELLO, 20I0), com o cruzamento das populações remanescentes entre si. Ainda, se as espécies presentes em pequenos fragmentos, circundados por monocultivos, e que não são resistentes aos agrotóxicos que até elas chegam pelo ar, solo e contaminação da água subterrânea (resistência que poucas espécies desenvolveram, como a buva - Conyza bonariensis - VARGAS et al., 2007), a tendência é que ocorra a morte destas populações a curto e médio prazos, o que elevaria o perigo de extinção para muitas espécies.

Considerando as circunstâncias expostas, além de 804 espécies já constarem como ameaçadas de extinção no estado (RIO GRANDE DO SUL, 20I4), é importante avaliar as diversas maneiras de garantir a perpetuação de espécies in situ e ex situ (dentro e fora de seus hábitats naturais, respectivamente). O Decreto $\mathrm{n}^{\circ}$ 4.339/2002 (BRASIL, 2002), que institui princípios e diretrizes para a implementação da Política Nacional da Biodiversidade, cita criar e consolidar programas de manejo e regulamentação de atividades relacionadas à utilização sustentável da biodiversidade e desenvolver e apoiar programas, ações e medidas que promovam a conservação e a utilização sustentável da agrobiodiversidade. A utilização sustentável da biodiversidade é uma estratégia de conservação pelo uso, ou seja, que o estímulo ao uso comercial de plantas e partes de plantas nativas visa o aumento do interesse da sociedade por produtos derivados da flora, criando maior interesse pela conservação das espécies (URRUTH, 2018). Dentro desta estratégia, o emprego de espécies nativas ornamentais tem sido defendido como forma de valorização e conservação da biodiversidade ex situ (SIMINSKI; REIS, 20I I), especialmente no ambiente urbano (THOMPSON et al., 2003; SILVA; PERELLÓ, 20I0).

Há um grande potencial ornamental ainda pouco empregado (STUMPF; BARBIERI; HEIDEN, 2009; SIMINSKI; REIS, 20I I; CARRION; BRACK, 20I2; MARCHI; BARBIERI, 20I5) dentre as mais de 4.700 espécies nativas do RS (FLORA DO BRASIL, 2020). Além disso, cresce no paisagismo a demanda por projetos que se insiram no contexto de sustentabilidade (CÉSAR; CIDADE, 2003; MEDEIROS, 2008; OLIVEIRA JÚNIOR et al., 2013) para os quais as espécies nativas se fazem necessárias, mas que ainda estão disponíveis em número de mudas e espécies insuficientes no mercado estadual. A produção de mudas e sementes para comercialização também surge como uma oportunidade de renda extra a pequenos agricultores, já que não há necessidade de plantio em grandes áreas para viabilizar a inserção no mercado (TOMBOLATO, 2008), podendo ser empregadas as espécies existentes na propriedade rural.

Considerando o incipiente uso, produção e comercialização de espécies nativas ornamentais, neste trabaIho realizou-se a revisão da legislação ambiental e agronômica no contexto do Estado do RS, apresentando as principais etapas legais para a produção e comercialização de mudas e sementes de espécies nativas para fins de uso ornamental. Discute-se, ainda, a necessidade de construção de políticas públicas ambientais que assegurem o uso destas de forma mais sustentável, garantindo a conservação genética das populações silvestres.

\section{Material e Métodos}

As informações acerca do uso comercial de plantas nativas ornamentais foram obtidas a partir de consultas às normas legais (decretos, instruções normativas, leis, portarias, resoluções) nas esferas ambiental e da agricultura, no âmbito do Estado do RS (legislação estadual e federal), vigentes durante no segundo semestre de 2018. A legislação foi consultada nas páginas oficiais dos seguintes órgãos: Secretaria do Meio Ambiente e Infraestrutura (SEMA/RS), Instituto Brasileiro do Meio Ambiente e dos Recursos Naturais Renováveis (IBAMA), Secretaria da Agricultura, Pecuária e Desenvolvimento Sustentável do Rio Grande do Sul (SEAPDR/RS) e Ministério da Agricultura, Pecuária e Abastecimento (MAPA). A Instrução Normativa SEMA nº 00I/2006 (RIO GRANDE DO SUL, 2006), que dispõe sobre as normas para regularização da coleta de folhas (frondes) da samambaia-preta (Rumohra adiantiformis (G.Forst.) Ching), foi encontrada, posteriormente, em consulta ao livro de Coelho-de-Souza, Kubo e Miguel (2008), mas não foi localizada nas páginas dos órgãos citados. 


\section{Resultados e discussões}

Uso de plantas nativas com fins econômicos no Rio Grande do Sul: bases legais, histórico e etapas para certificação

Foram consultadas I.I58 normas legais sendo que, dentre estas, 25 estaduais e 39 federais (Anexo I) apresentavam alguma informação acerca da produção e comercialização de mudas e sementes de espécies nativas para fins ornamentais no contexto do RS.

Segundo o artigo 30 da Lei Estadual no 9.519/1992 (RIO GRANDE DO SUL, 1992), que Institui o Código Florestal do Estado do Rio Grande do Sul e dá outras providências, ficam proibidos a coleta, o comércio e o transporte de plantas ornamentais oriundas de florestas nativas, ou seja, não é possível realizar coleta diretamente na natureza para comercialização. Esta proibição se faz necessária devido ao saque que ocorreu (e ainda ocorre) de espécies pertencentes principalmente às famílias Orchidaceae, Bromeliaceae e Dicksoniaceae em florestas nativas, assim como Cactaceae e Arecaceae em outras formações vegetais, além da ocorrência de biopirataria no Estado (ANNES, 2006; BENCKE, 20 I6). Para tanto, o artigo $7^{\circ}$ da Lei Estadual $n^{\circ}$ I I.520/2000 (RIO GRANDE DO SUL, 2000), que Institui o Código Estadual de Meio Ambiente, expõe que a utilização dos recursos ambientais com fins econômicos, dependerá de autorização do órgão competente, na forma da lei. Compreende-se, com base neste artigo, que é possível realizar comercialização de recursos vegetais desde que haja autorização do órgão responsável, expresso também no artigo 37 da Lei Federal no I2.65 I/20 I 2 (BRASIL, 20 I 2), que dispõe sobre a proteção da vegetação nativa (Art. 37: "O comércio de plantas vivas e outros produtos oriundos da flora nativa dependerá de licença do órgão estadual competente do SISNAMA e de registro no Cadastro Técnico Federal de Atividades Potencialmente Poluidoras ou Utilizadoras de Recursos Ambientais [...]").

O artigo 157 da Lei Estadual no I I.520/2000 (RIO GRANDE DO SUL, 2000) alerta que na utilização dos recursos da flora serão considerados os conhecimentos ecológicos de modo a se alcançar sua exploração racional e sustentável, evitando-se a degradação e destruição da vegetação e o comprometimento do ecossistema dela dependente. Também o artigo 162, desta mesma lei, expõe que a utilização de recursos provenientes de floresta ou outro tipo de vegetação lenhosa nativa será feita de acordo com projeto que assegure manejo sustentado do recurso, através do sistema de regime jardinado, de acordo com o Código Florestal do Estado. Portanto, ambas as legislações, estadual e federal, consentem quanto à possibilidade de uso da biodiversidade nativa com fins comerciais, desde que autorizado pelo órgão competente e seguindo critérios que não comprometam o ambiente natural e as espécies-alvo.

Há pelo menos duas espécies nativas cujo uso apresentam regulamentação específica pela Secretaria do Meio Ambiente e Infraestrutura (SEMA/RS). A Instrução Normativa SEMA n 00I/2006 (RIO GRANDE DO SUL, 2006) dispõe sobre as normas para regularização da coleta de folhas (frondes) da samambaia-preta (Rumohra adiantiformis (G.Forst.) Ching), resultado de inúmeros estudos (COELHO-DE-SOUZA; KUBO; MIGUEL, 2008) sobre esta samambaia utilizada em arranjos florais. Também com base em pesquisa (MAURMANN, 20I2), a Portaria SEMA n 46/20I4 (RIO GRANDE DO SUL, 20I4) dispõe sobre as normas para regularização da colheita de folhas (frondes) e frutos do Butia catarinensis (butiá-da-praia), cujas folhas são utilizadas para artesanato e os frutos para alimentação e comercialização.

Além do uso de folhas, a comercialização de plantas ornamentais é realizada especialmente por meio de mudas, plantas em vasos (plantas vivas), sementes, flores de corte, bulbos, folhagens e leivas (no caso de gramíneas) (NEVES et al., 2015). A legislação ambiental se refere a este conjunto, dentre outras denominações e usos, como "recursos não madeireiros", uma vez que os "recursos madeireiros", ou seja, a exploração comercial de madeira, foi das primeiras categorias a ser licenciada, juntamente com modalidades de conversão do uso do solo através da supressão de florestas nativas (URRUTH, 20I8). Segundo Urruth (2018), apenas por volta do ano de 2014 a SEMA/RS estabeleceu procedimentos para legalização da exploração comercial da flora, incluindo produtos florestais não madeiráveis. Isso significa que qualquer utilização comercial de recursos nativos não madeireiros no Estado antes desta data, possivelmente, não seria autorizada pelo órgão ambiental, apesar desta possibilidade já constar em legislações federal e estadual.

Atualmente são necessárias determinadas etapas para obtenção de autorização para emprego comercial de recursos não madeireiros, fases muitas vezes desconhecidas por produtores ou comerciantes. $O$ uso comercial de espécies nativas é regido pela legislação ambiental e agronômica, uma vez que os diferentes órgãos 
governamentais regulam, controlam ou fiscalizam diferentes etapas da propagação e comercialização de plantas (sejam mudas, bulbos e outros) ou sementes. Para este caso, por exemplo, a principal norma agronômica é a Instrução Normativa MAPA n 17/20I7 (BRASIL, 2017) que, conforme o artigo I regulamenta a produção, a comercialização e a utilização de sementes e mudas de espécies florestais ou de interesse ambiental ou medicinal, nativas e exóticas, visando garantir sua procedência, identidade e qualidade. A Tabela I apresenta, de maneira bastante sintetizada, as principais etapas e em quais órgãos governamentais deve ser requerida autorização para produção e comercialização de espécies nativas vegetais de interesse ornamental.

Tabela I - Síntese de requerimentos e cadastros por órgão governamental para solicitação de autorização para produção e comercialização de espécies nativas ornamentais no Rio Grande do Sul.

\begin{tabular}{|c|c|c|c|c|}
\hline & & Mudas & Sementes & Norma legal \\
\hline I & $\begin{array}{c}\text { Órgão Ambiental } \\
\text { Estadual (SEMA/RS) }\end{array}$ & $\begin{array}{l}\text { Requerimento para uso. } \\
\text { Cadastro do viveiro de } \\
\text { produção. }\end{array}$ & $\begin{array}{l}\text { Requerimento para uso. } \\
\text { Cadastro do viveiro de } \\
\text { produção. }\end{array}$ & $\begin{array}{l}\text { Lei Estadual } n^{\circ} \\
\text { I I. } 520 / 2000 \text { (RIO } \\
\text { GRANDE DO SUL, } \\
\text { 2000). }\end{array}$ \\
\hline 2 & $\begin{array}{l}\text { Órgão Ambiental } \\
\text { Federal (IBAMA) }\end{array}$ & $\begin{array}{l}\text { Cadastrar-se no Cadastro } \\
\text { Técnico Federal de Atividades } \\
\text { Potencialmente Poluidoras } \\
\text { ou Utilizadoras de Recursos } \\
\text { Ambientais. }\end{array}$ & $\begin{array}{l}\text { Cadastrar-se no Cadastro } \\
\text { Técnico Federal de Atividades } \\
\text { Potencialmente Poluidoras } \\
\text { ou Utilizadoras de Recursos } \\
\text { Ambientais. }\end{array}$ & $\begin{array}{l}\text { Instrução Normativa no } \\
\text { 6/20I3 (BRASIL, 20I3). }\end{array}$ \\
\hline 3 & $\begin{array}{l}\text { Ministério da } \\
\text { Agricultura, Pecuária } \\
\text { e Abastecimento } \\
\text { (MAPA) }\end{array}$ & $\begin{array}{l}\text { Acima de } \mathbf{1 0 . 0 0 0} \text { mudas } \\
\text { por ano, cadastrar-se no } \\
\text { RENASEM (Registro Nacional } \\
\text { de Sementes e Mudas). }\end{array}$ & $\begin{array}{l}\text { Cadastrar-se no RENASEM } \\
\text { (Registro Nacional de } \\
\text { Sementes e Mudas) }\end{array}$ & $\begin{array}{l}\text { Instrução Normativa } \\
\text { MAPA n० I7/2017 } \\
\text { (BRASIL, 20I7). }\end{array}$ \\
\hline 4 & $\begin{array}{l}\text { Secretaria da } \\
\text { Agricultura, Pecuária } \\
\text { e Desenvolvimento } \\
\text { Sustentável/RS } \\
\text { (SEAPDR/RS) }\end{array}$ & $\begin{array}{c}\text { Quando a atividade } \\
\text { desenvolvida é apenas } \\
\text { comércio: cadastrar-se no } \\
\text { RENASEM (Registro Nacional } \\
\text { de Sementes e Mudas) pelo } \\
\text { órgão estadual. }\end{array}$ & $\begin{array}{c}\text { Quando a atividade } \\
\text { desenvolvida é apenas } \\
\text { comércio: cadastrar-se no } \\
\text { RENASEM (Registro Nacional } \\
\text { de Sementes e Mudas) pelo } \\
\text { órgão estadual. }\end{array}$ & $\begin{array}{c}\text { Instrução Normativa } \\
\text { MAPA n I } 7 / 2017 \\
\text { (BRASIL, 20 I 7). Decreto } \\
n^{\circ} 5.153 \text {, de } 23 \text { de julho } \\
\text { de } 2004 \text { (Art. I 26) } \\
\text { (BRASIL, 2004). }\end{array}$ \\
\hline
\end{tabular}

A Tabela I segue ordem lógica, devendo-se iniciar pelo requerimento para uso de espécies vegetais nativas ao órgão ambiental estadual. Este analisará as características de determinada espécie, verificando se o uso da mesma trará riscos ou não para sua conservação conforme artigo I 57 da Lei Estadual n I I.520/2000 (RIO GRANDE DO SUL, 2000), definindo pela autorização ou indeferimento do pedido.

De acordo com a síntese disposta na Tabela I, há dois pontos principais a serem observados. O primeiro, entre a produção de mudas e sementes. Caso a produção de mudas ultrapasse 10.000 unidades por ano, é necessário realizar cadastro no Registro Nacional de Sementes e Mudas (RENASEM), enquanto a produção de sementes deve ser cadastrada independentemente da quantidade produzida. $O$ cadastro no RENASEM exige inúmeras normas e controles (como documentação acerca das espécies, contendo nome científico, coordenadas geográficas do local de coleta, identificação dos lotes de sementes coletadas, necessidade de responsável técnico), o que desestimula a iniciativa de pessoas no ramo ou inviabiliza pequenas produções, necessitando de uma organização a partir de empresas ou cooperativas. Outra diferença se dá na atividade de comércio, pois se esta é a única atividade exercida, ou seja, não há produção de sementes, por exemplo, o cadastro no RENASEM deverá ser realizado junto à Secretaria da Agricultura, Pecuária e Desenvolvimento Sustentável do Estado (SEAPDR/RS), e não no Ministério da Agricultura, Pecuária e Abastecimento (MAPA). 
É possível compatibilizar uso sustentável e impulsionar a produção de espécies vegetais nativas ornamentais?

\section{Desafios a serem superados}

É papel do poder público criar normas para preservar e restaurar os processos ecológicos essenciais e prover o manejo ecológico das espécies e ecossistemas (Artigo 225, § Iº, item I) (BRASIL, 1988). Apesar da existência de normas legais bastante restritivas, estas raramente se impõem como uma condição impeditiva dos impactos gerados pelo modelo de desenvolvimento produtivista, principalmente pela grande dificuldade de sua aplicação e fiscalização e, por outro lado, tem-se o estímulo a modelos produtivistas que incentivam o agronegócio (COELHO-DE-SOUZA; PEREIRA; KUBO, 2008). Isso é facilmente observável quando se compara, por exemplo, a atual necessidade de inúmeros procedimentos para produção de mudas e sementes nativas (vide tabela I e Instrução Normativa MAPA n I7/2017) (BRASIL, 20I7), enquanto para a conversão de vegetação campestre nativa para uso alternativo do solo, no bioma Pampa por exemplo, bastaria realizar apenas uma solicitação para um único órgão ambiental (RIO GRANDE DO SUL, 2018). Este exemplo demonstra que a legislação inviabiliza, muitas vezes, as atividades de uso sustentável em detrimento de atividades degradadoras do ambiente.

Para processos de restauração de áreas degradadas observam-se dificuldades semelhantes às relatadas para atividades de uso sustentável (DURIGAN et al., 2010), especialmente quando a legislação impõe a necessidade de padrões para comercialização de sementes (SCHMIDT et al., 20I8) sem considerar a diversidade de espécies vasculares do Brasil (FORZZA et al., 20I2). Schmidt et al. (2018) explicam que o governo brasileiro estabeleceu protocolos de qualidade de sementes (BRASIL, 2009) com base nas Regras Internacionais de Testes de Sementes. E, para tanto, exigem protocolos específicos para cada espécie, desde o pré-tratamento (limpeza de sementes, quebra de dormência) e testes de germinação (substrato, temperatura e número de dias para avaliação da germinação). São necessários inúmeros estudos para concluir cada um destes parâmetros para uma única espécie, o que demanda muito tempo em pesquisas (MIURA et al., 20I2). Conforme Schmidt et al. (2018), dentre as 300 espécies florestais para as quais já haviam protocolos de qualidade de sementes validados e publicados em documentos legais, menos de 50 eram espécies nativas. Isso significa que sementes das demais espécies nativas do Brasil, não possuindo ainda testes específicos aprovados, não estariam aptas à comercialização. Segundo os autores, estes regulamentos destacam a necessidade do desenvolvimento de testes rápidos de qualidade de sementes, como o teste de tetrazólio para viabilidade de sementes, técnicas de quebra de dormência e métodos de armazenamento simplificados. Estes, que poderiam ser aplicados na produção de sementes em comunidades locais coletora de sementes, incluindo o conhecimento da comunidade para manejo das mesmas.

Freire, Urzedo e Piña-Rodrigues (20I7) destacam que apesar de avanços, ainda há muitos gargalos para a produção de sementes, como a desarticulação de sistemas institucionais e de arranjos comerciais, excessos burocráticos, inconstâncias das políticas públicas, falta de tecnologias apropriadas para produção e análise de sementes e planejamento de longo prazo das ações governamentais em relação à conservação e restauração. Outros trabalhos discutem a necessidade de simplificação dos requerimentos legais, especialmente para ações de restauração ecológica (DURIGAN et al., 20I0; SCHMIDT et al., 20I8).

\section{Desafios já superados}

O atual cenário de degradação da vegetação no Brasil deveria ser motivo suficiente para que novas formas de uso sustentável da flora nativa fossem incentivadas. Apesar da falta de estímulo legal e governamental, o estado do RS avançou na facilitação do processo de autorização para uso sustentável da vegetação: I) desde 2014 há possibilidade de certificação de uso não-madeireiro de espécies nativas (URRUTH, 20I8); 2) desde 2017 o requerimento de autorização pode ser realizado via internet pelo sistema SOL (Sistema Online de Licenciamento Ambiental - www.sol.rs.gov.br); 3) para a produção familiar há dispensa de responsável técnico e isenção de taxas (URRUTH, 20I8). Urruth (20l8) comenta que já são conhecidas diversas ações de produção de mudas e plantios de butiazeiros (Butia odorata (Barb.Rodr.) Noblick) em decorrência do processo de aumento de interesse pela espécie no litoral sul, o que se deve à certificação concedida a extrativistas nesta 
região. Também há relatos de crescimento da demanda por produtos elaborados a partir de frutas nativas (PETTENON; RAMOS; BASTOS, 20I2; KÖHLER; BRACK, 20I6; DAIROT, 20I8; PINTO, 20I9).

O cenário atual, resultado das etapas pelas quais passaram as políticas públicas, se deve especialmente à demanda de diversos atores sociais. Köhler e Brack (2016) relatam que foram múltiplos os protagonistas, em diferentes setores da sociedade, que atuaram ora de forma isolada, ora em conjunto, mas com propósitos muito semelhantes que possibilitaram, por exemplo, o acesso à exploração comercial de frutas nativas. Da mesma forma ocorreu a legalização do extrativismo de frondes de samambaia-preta e de butiá-da-praia (RIO GRANDE DO SUL, 2006; 20I4). As frondes de samambaia-preta já têm uso consolidado para arranjos florais (COELHO-DE-SOUZA; KUBO; MIGUEL, 2008). Com relação às espécies ornamentais nativas para uso no paisagismo, o comércio resume-se a mudas de poucas espécies frente à grande biodiversidade florística do Estado (ROLIM, 2018). E estas são, geralmente, resultado de pesquisas efetuadas no exterior (STUMPF; BARBIERI; HEIDEN, 2009), ou seja, não são provenientes de produção local, sendo questionável a contribuição à conservação destas espécies, uma vez que é desconhecida a região de origem dos espécimes ou mesmo devido às alterações genéticas ocorridas nos processos de "melhoramento".

\section{Conservação genética}

Em conjunto ao incentivo para uso sustentável de espécies vegetais nativas, são necessárias políticas públicas complementares com foco na conservação genética. Silva e Perelló (2010) defendem que ainda há pontos a serem melhor definidos para a condução da estratégia de conservação ex situ por meio do uso ornamental. A principal questão refere-se às consequências quanto à translocação de espécies para outras regiões, criando o risco de cruzamento entre diferentes populações silvestres, ou risco da proliferação de apenas um determinado genoma em viveiros (SILVA; PERELLÓ, 2010). Um mecanismo possível de atender esta demanda seria a definição de zonas de coletas, como ocorre para coleta de sementes com fins de restauração ecológica em diversos países (RANDALL; BERRANG, 2002; MCKAY et al., 2005; MILLAR; BYRNE; COATES, 2008; BIERNASKI; HIGA; SILVA, 20I2; JORGENSEN et al., 20I4), mas ainda pouco empregado no Brasil. As zonas de coleta têm como base o princípio de que grupos de indivíduos da mesma espécie, estabelecidos em diferentes regiões, com características ambientais próprias, tendem a diferenciar-se geneticamente formando populações (BIERNASKI; HIGA; SILVA, 20I2). Estudos realizados por Miller et al. (20I0) na Austrália, indicam que as ecorregiões podem ser limites úteis para definição de zonas de coletas, especialmente em regiões com pouca variação topográfica ou climática. Para o RS é imprescindível e urgente o estabelecimento, com identificação e mapeamento, de regiões de coletas de sementes para espécies nativas, juntamente com outros mecanismos que regulem a comercialização de mudas e sementes.

\section{Considerações finais}

A análise da legislação estadual e federal fundamenta que o uso comercial de plantas nativas com fins ornamentais é regrado, mas não proibido. Apesar de entraves burocráticos terem restringido este uso até 2014 no Rio Grande do Sul, atualmente pode ser autorizado pelo órgão ambiental estadual mediante regras que caracterizem o uso sustentável, o que depende de cada espécie. Há necessidade de simplificação dos requerimentos legais para uso de plantas nativas. Foram citados exemplos bem sucedidos de uso da flora nativa, demonstrando que o estímulo à produção destas para o emprego ornamental tende a ter resultados também positivos. Com o devido cuidado a grupos de espécies que historicamente sofreram e sofrem extrativismo e biopirataria, além das espécies ameaçadas de extinção, é imprescindível avançar no estímulo a atividades de uso sustentável, ampliando a divulgação e a informação à população, juntamente com mecanismos de conservação genética e fiscalização ambiental. $O$ uso da biodiversidade valoriza $\circ$ ato daquele que conservou, e $\circ$ amplia na medida em que se cria a possibilidade de uso e valoração do bem conservado. 


\section{Referências}

ANNES, M. H. IBAMA/RS apreende flora do Pampa com estrangeiros suspeitos de biopirataria. Ambiente Brasil, I5 nov. 2006. Disponível em: <http://noticias.ambientebrasil.com.br/clipping/2006/I I/I5/27847-ibamars-apreende-flora-do-pampa-com-estrangeiros-suspeitos-de-biopirataria.html>. Acesso em: 03 mar. 2019.

BENCKE, G. A. Biodiversidade. In: CHOMENKO, L.; BENCKE, G. A. (Org.). Nosso Pampa Desconhecido. Porto Alegre: Fundação Zoobotânica do Rio Grande do Sul, 20I6. p. 6I-75.

BIERNASKI, F. A.; HIGA, A. R.; SILVA, L. D. Variabilidade genética para caracteres juvenis de progênies de Cedrela fissilis Vell: subsídio para definição de zonas de coleta e uso de sementes. Revista Árvore, Viçosa, v. 36, n. I, p. 49-58, jan./ fev. 2012 .

BRASIL. Constituição da República Federativa do Brasil de 1988. Disponível em: <http://www.planalto.gov.br/ ccivil_03/constituicao/constituicaocompilado.htm>. Acesso em: out. 20 I8.

BRASIL. Decreto n 4.339, de 22 de agosto de 2002. Institui princípios e diretrizes para a implementação da Política Nacional da Biodiversidade. Disponível em: http://www.planalto.gov.br/ccivil_03/decreto/2002/D4339.htm. Acesso em: fev. 2019.

BRASIL. Decreto n 5. I53, de 23 de julho de 2004. Aprova o Regulamento da Lei $n^{\circ} 10.7$ I I, de 5 de agosto de 2003 , que dispõe sobre o Sistema Nacional de Sementes e Mudas - SNSM, e dá outras providências. Disponível em: <http:// www.planalto.gov.br/ccivil_03/_ato2004-2006/2004/decreto/d5I53.htm >. Acesso em: fev. 2019.

BRASIL. Lei Federal n I2.65 I, de 25 de maio de 2012 . Dispõe sobre a proteção da vegetação nativa; altera as Leis nos 6.938, de 31 de agosto de 198I, 9.393, de 19 de dezembro de 1996, e I I.428, de 22 de dezembro de 2006; revoga as Leis nos 4.77I, de 15 de setembro de 1965, e 7.754, de 14 de abril de 1989, e a Medida Provisória no 2.166-67, de 24 de agosto de 200I; e dá outras providências. Disponível em: <http://www.planalto.gov.br/ccivil_03/_ato20II20I4/20I2/lei/ll265 I.htm>. Acesso em: fev. 2019.

BRASIL. Instrução Normativa n 6, de 15 de março de 20 I3. Disponível em: <https://www.ibama.gov.br/phocadownload/ctf/20I8/lbama-IN-6-20I3-compilada-IN-I I-20I8.pdf>. Acesso em: fev. 2019.

BRASIL. Instrução Normativa MAPA n I7, de 26 de abril de 20 I7. Disponível em: <http://www.in.gov.br/materia/-/asset_publisher/Kujrw0TZC2Mb/content/id/20 I86073/dol I-2017-04-28-instrucao-normativa-n- I 7-de-26-de-abril-de-2016-20185922>. Acesso em: out. 2018.

BRASIL. Ministério da Agricultura, Pecuária e Abastecimento. Secretaria de Defesa Agropecuária. Regras para análise de sementes. Brasília: MAPA/ACS, 2009. p. 399.

CARRION, A. A.; BRACK, P. Eudicotiledôneas ornamentais dos campos do bioma Pampa no Rio Grande do Sul. Revista Brasileira de Horticultura Ornamental, v. I8, n. I, p. 23-37, 2012.

CARVALHO, P. C. F.; SANTOS, D. T.; GONÇALVES, E. N.; PINTO, C. E.; NEVES, F. P.; TRINDADE, J. K.; BREMM, C.; MEZZALIRA, J. C.; NABINGER, C.; JACQUES, A. V. Á. Lotação Animal em Pastagens Naturais: políticas, pesquisas, preservação e produtividade. In: PILLAR, V. P.; MULLER, S. C.; CASTILHOS, Z. M. S.; JACQUES, A. V. A. (Org.). Campos Sulinos: Conservação e Uso Sustentável da Biodiversidade. Brasília: Ministério do Meio Ambiente, 2009. p. 214-228.

CÉSAR, L. P. M.; CIDADE, L. C. Ideologia, visões de mundo e práticas socioambientais no paisagismo. Sociedade e Estado, v. I8, p. II5-136, 2003.

COELHO-DE-SOUZA, G.; KUBO, R.; MIGUEL, L. A. (Org.). Extrativismo da samambaia-preta no Rio Grande do Sul. Porto Alegre: Editora da UFRGS, 2008. 264p.

COELHO-DE-SOUZA, G.; PEREIRA, F. M.; KUBO, R. Contextualização da problemática ambiental com ênfase nos aspectos jurídicos. In: COELHO-DE-SOUZA, G., KUBO, R., MIGUEL, L. A. (Org.). Extrativismo da samambaia-preta no Rio Grande do Sul. Porto Alegre: Editora da UFRGS, 2008. p. 1 7-37. 
DAIROT, G. Frutas nativas tentam recuperar mercado. Jornal do Comércio, 05 mar. 2018. Disponível em: <https:// www.jornaldocomercio.com/_conteudo/2018/02/cadernos/empresas_e_negocios/613849-frutas-nativas-tentam-recuperar-mercado.html>. Acesso em: mar. 2019.

DURIGAN, G.; ENGEL, V. L.; TOREZAN, J. M. D.; MELO, A. C. G.; MARQUES, M. C. M.; MARTINS, S. V.; REIS, A.; SCARANO, F. R. Normas jurídicas para a restauração ecológica: uma barreira a mais a dificultar o êxito das iniciativas? Revista Árvore, v. 34, p. 47I-485, 2010.

FLORA DO BRASIL. Jardim Botânico do Rio de Janeiro. Disponível em: http://floradobrasil.jbrj.gov.br/. Acesso em: 3 out. 2020.

FORZZA, R. C. et al. New Brazilian floristic list high lights conservation challenges. Bioscience, v. 62, p. 39-45, 2012.

FREIRE, J. M.; URZEDO, D. I.; PIÑA-RODRIGUES, F. C. M. A realidade das sementes nativas do Brasil: desafios e oportunidades para a produção em larga escala. Seed News, v. I, p. 24-28, 2017.

IBAMA - Instituto Brasileiro do Meio Ambiente e dos Recursos Naturais Renováveis. IBAMA embarga I,2 mil hectares de Mata Atlântica e aplica $\mathbf{R} \mathbf{9 , 4}$ milhões em multas no RS. 2017. Disponível em: https://www.ibama.gov.br/ noticias/422-20 17// I68-ibama-embarga-I-2-mil-hectares-de-mata-atlantica-e-aplica-r-9-4-milhoes-em-multas-no-rs. Acesso em: mai. 2019.

IBAMA - Instituto Brasileiro do Meio Ambiente e dos Recursos Naturais Renováveis. Histórico de comercialização 2000-2017. 2018. Disponível em: http://www.ibama.gov.br/agrotoxicos/relatorios-de-comercializacao-de-agrotoxicos. Acesso em: 02 mar. 2019.

IBGE - Instituto Brasileiro de Geografia e Estatística. Censo Agropecuário 1995-1996. 1996. Disponível em: <https://www.ibge.gov.br/estatisticas-novoportal/economicas/agricultura-e-pecuaria/20700-1995- 1996-censoagrol 995. html?edicao $=18356 \& \mathrm{t}=$ destaques $>$. Acesso em: 02 mar. 2019.

IBGE - Instituto Brasileiro de Geografia e Estatística. Censo Agro 2017. 2017. Disponível em: <https://censos.ibge. gov.br/agro/20 I7/templates/censo_agro/resultadosagro/pecuaria.html?localidade $=43 \&$ tema $=75652>$. Acesso em: 02 mar. 2019.

JORGENSEN, M. H., ELAMEEN, A., KLEMSDAL, S.; FJELLHEIM, S. Use of molecular markers for defining site-specific seed material for restoration in Norway. In: Kiehl, K.; Kirmer, A.; Shaw, N.; Tischew, S. Guidelines for Native Seed Production and Grassland Restoration (eds), Cambridge Scholars Publishing, Newcastle upon Type, 2014. p. 57-74.

KÖHLER, M.; BRACK, P. Frutas Nativas no Rio Grande do Sul: cultivando e valorizando a diversidade. Revista Agriculturas, v. 13, p. 7-15, 2016.

MCKAY, J. K.; CHRISTIAN, C. E.; HARRISON, S.; RICE, K. J. “How Local Is Local?" - A review of practical and conceptual issues in the genetics of restoration. Restoration Ecology, v. I3, n. 3, p. 432-440, 2005.

MARCHI, M. M., BARBIERI, R. L. (Org.). Cores e formas no Bioma Pampa - Gramíneas ornamentais nativas. Pelotas: Embrapa Clima Temperado, 2015. 200p.

MAURMANN, K. Sustentabilidade do manejo tradicional da folha de Butia capitata e a conservação dos butiazais. 20I2. 25 f. Dissertação (Mestrado em Ecologia) - Universidade Federal do Rio Grande do Sul.

MEDEIROS, J. M. M. Visões de um paisagismo ecológico na orla do Lago Paranoá. Brasília, DF. 2008. I86 f. Dissertação (Mestrado em Arquitetura e Urbanismo) - Universidade de Braślia.

MILLAR, M.A.; BYRNE, M.; COATES, D. J. Seed collection for revegetation: guidelines for Western Australian flora. Journal of the Royal Society of Western Australia, v. 91, p. 293-299, 2008.

MILLER, S. A.; BARTOW, A.; GISLER, M.; WARD, K.; YOUNG, A. S.; KAYE, T. N. Can an ecoregion serve as a seed transfer zone? Evidence from a common garden study with five native species. Restoration Ecology, v. 19, n. 20I, p. 268-276, 2010. 
MIURA A. K.; SANTANNA, D.; GUARINO, E. S. G.; OVERBECK, G.; BOLDRINI, I.; MAHLER JÚNIOR, J. K. F.; OLIVEIRA, J. C. P.; VALLS, J. F. M.; TYMUS, J. R. C.; DERETI, L. P., CHOMENKO, L., KÖPP, M. Produção de propágulos para suporte à adequação de áreas campestres do bioma Pampa à lei $\mathbf{n}^{\circ}$ I2.65 I, de 25 de maio de 2012 (Lei de Proteção da Vegetação Nativa). (Nota Técnica). Disponível em: <https://www.embrapa.br/ documents/ I 354346/ I 3488452/Nota + T\%C3\%A9cnica +-+Produ\%C3\%A7\%C3\%A3o+de+sementes + bioma +Pampa/4c0ed925-f203-40b3-9889-0162db7le657>. Acesso em: mai. 2019.

NEVES, M. F.; PINTO, M. J. .; LIMA JÚNIOR, J. C.; NAKATANI, J. K.; CARMO NETO, L. M.; LIMA, L. A. C. V.; KALAKI, R. B. \& CAMARGO, R. B. Mapeamento e quantificação da cadeia de flores e plantas ornamentais do Brasil. São Paulo: OCESP, 2015. I 3 Ip.

OLIVEIRA JÚNIOR, C. J. F; GONÇALVES, F. S.; COUTO, F;; MATAJS, L. Potencial das espécies nativas na produção de plantas ornamentais e paisagismo agroecológico. Revista Brasileira de Agroecologia, v.8, n.3, p. I90-200, 2013.

OVERBECK, G. E.; MÜLLER, S. C.; FIDELIS, A. T.; PFADENHAUER, J.; PILLAR, V. P.; BLANCO, C. C.; BOLDRINI, I. I.; BOTH, R.; FORNECK, E. D. Os Campos Sulinos: Um Bioma Negligenciado. In: PILLAR, V. P.; MULLER, S. C.; CASTILHOS, Z. M. S.; JACQUES, A. V. A. (Org.). Campos Sulinos: Conservação e Uso Sustentável da Biodiversidade. Brasília: Ministério do Meio Ambiente, 2009. p. 26-4I.

PETTENON, L. S.; RAMOS, M.; BASTOS, V. Agricultura familiar e agroecologia. Geração de renda e qualidade de vida no litoral norte do RS. Boletim Informativo, n. 6, p. 3, 2012.

PINTO, E. Pesquisas potencializam cultivo e qualificam exploração econômica do butiá. Disponível em: <https://www.agricultura.rs.gov.br/pesquisas-potencializam-cultivo-e-qualificam-exploracao-economica-do-butia $>$. Acesso em: mai. 2019.

MAPBIOMAS. Coleção 3.0 da Série Anual de Mapas de Cobertura e Uso de Solo do Brasil. [2020] Disponível em: https://plataforma.brasil.mapbiomas.org/. Acesso em: 03 out. 2020.

RANDALL, W. K.; BERRANG, P. Washington tree seed transfer zones. Washington Department of Natural Resources, Olympia, Washington, D.C. 2002.

RIO GRANDE DO SUL. Decreto n 52.109, de 19 de dezembro de 20 I4. Declara as espécies da flora nativa ameaçadas de extinção no RS. Porto Alegre, RS: Diário Oficial, 02 dez. 2014. Disponível em: <http://www.fzb.rs.gov. br/upload/2014I222103647doe.pdf>. Acesso em: mar. 2019.

RIO GRANDE DO SUL. Instrução Normativa SEMA n $001 / 2006$, de 3 I de julho de 2006. Dispõe sobre as Normas para a regularização da coleta de folhas (frondes) da samambaia-preta (Rumohra adiantiformis (G.Forst.) Ching). Porto Alegre, 04 ago. 2006.

RIO GRANDE DO SUL. Lei n 9.5 I9, de 2 I de janeiro de 1992. Institui o Código Florestal do Estado do Rio Grande do Sul e dá outras providências. Disponível em: <http://www.al.rs.gov.br/filerepository/replegis/arquivos/09.5I9.pdf>. Acesso em: jul. 2018.

RIO GRANDE DO SUL. Lei n⿳ I I.520, de 3 de agosto de 2000. Institui o Código Estadual do Meio Ambiente do Estado do Rio Grande do Sul e dá outras providências. Disponível em: <http://www.al.rs.gov.br/legiscomp/arquivo. asp?idNorma = I I \&tipo = pdf > . Acesso em: jul. 2018.

RIO GRANDE DO SUL. Portaria SEMA n⿳ 46/20I4. Dispõe sobre as normas para regularização da colheita de folhas (frondes) e frutos do Butia catarinensis (butiá-da-praia). Disponível em: <https://www.legisweb.com.br/legislacao/?id=272540>. Acesso em: jul. 2018.

RIO GRANDE DO SUL. Resolução CONSEMA 372/2018. Dispõe sobre os empreendimentos e atividades utilizadores de recursos ambientais, efetiva ou potencialmente poluidores ou capazes, sob qualquer forma, de causar degradação ambiental, passíveis de licenciamento ambiental no Estado do Rio Grande do Sul, destacando os de impacto de âmbito local para o exercício da competência municipal no licenciamento ambiental. Disponível em: <https://www.sema.rs. gov.br/upload/arquivos/20 I803/I5 I 20855-372-20 I8-atividades-licenciavies-revisao-288.pdf>. Acesso em: mai. 20 I 9. 
ROLIM, Rosângela Gonçalves. Do potencial ao ornamental: subsídios para a difusão da biodiversidade vegetal nativa do Rio Grande do Sul no paisagismo. 2018. Dissertação (Mestrado) - Curso de Mestrado Profissional em Ambiente e Sustentabilidade, Universidade Estadual do Rio Grande do Sul, São Francisco de Paula, 2018.

SCHMIDT, I. B.; URZEDO, D. I.; PIÑA-RODRIGUES, F. C. M.; VIEIRA, D. L. M.; REZENDE, G. M.; SAMPAIO, A. B.; JUNQUEIRA, R. P. Community-based native seed production for restoration in Brazil? The role of science and policy. Plant Biology, v. 5, p. I-9, 2018.

SILVA, J. G.; PERELLÓ, L. F. C. Conservação de espécies ameaçadas do Rio Grande do Sul através de seu uso no paisagismo. Revista da Sociedade Brasileira de Arborização Urbana, v. 5, p. 25-45, 2010.

SIMINSKI, A.; REIS, A. Espécies Ornamentais Nativas da Região Sul do Brasil. In: CORADIN, L.; SIMINSKI, A.; REIS, A. (Org.). Espécies nativas da flora brasileira de valor econômico atual ou potencial: plantas para o futuro- Região Sul. Brasília: Gráfica Diplomata -MMA, 20I I. p. 729-733.

STUMPF, E. R. T.; BARBIERI, R. L.; HEIDEN, G. (Org.). Cores e formas no Bioma Pampa: plantas ornamentais nativas. Pelotas: Embrapa Clima Temperado, 2009. 276p.

TOMBOLATO, A. F.C. Potencial ornamental de espécies nativas. Revista Brasileira de Horticultura Ornamental, v. I4, n. I, p. 27-28, 2008.

THOMPSON, K.; AUSTIN, K. C.; SMITH, R. M.; WARREN, P. H.; ANGOLD, P. G.; GASTON, K. J. Urban domestic gardens (I): Putting small-scale plant diversity in context. Journal of Vegetation Science, v. I4, n. I, 7I-78, 2003.

URRUTH, L. M. Certificação para uso sustentável da flora nativa do Rio Grande do Sul. In: Anais do III Seminário Sul-Brasileiro sobre a Sustentabilidade da Araucária. Tapera: Livraria e Editora Werlang Ltda, 2018. p. 28-3I.

VARGAS, L.; BIANCHI, M. A.; RIZZARDI, M. A.; AGOSTINETTO, D.; DAL MAGRO, T. Buva (Conyza bonariensis) resistente ao glyphosate na região sul do Brasil. Planta Daninha, v. 25, p. 573-578, 2007.

VÉlEZ-MARTIN, E.; ROCHA, C. H.; BLANCO, C.; AZAMBUJA, B. O.; HASENACK, H.; PILLAR, V. P. Conversão e Fragmentação. In: LANGE, O.; PILLAR, V. P. (Org.). Os Campos do Sul. Porto Alegre: UFRGS, 20I5. p. I23-I29.

VIEIRA, M. S.; OVERBECK, G. E. Recuperação dos Campos. In: LANGE, O.; PILLAR, V. P. (Org.). Os Campos do Sul. Porto Alegre: UFRGS, 2015. p. 149-152.

WENZEL, F. IBAMA tenta frear avanço da degradação dos campos gaúchos. $\mathbf{O}$ Eco, quarta-feira, 3 de outubro de 2018. Disponível em: https://www.oeco.org.br/reportagens/ibama-tenta-frear-avanco-da-degradacao-dos-campos-gauchos/. Acesso em: mai. de 2018. 